not selfisb and is willing to divide with the other children. He is cleanly in his habits and not destructive with his toys. The imitative trait mentioned previousiy is very noticeable; his parents spoke of it independently of any questioning. He imitates many of the actions of his parents and playmates with surprising accuracy, and is even now learning much of his specch by imitating his sister, who is but 2 years of age. He has a decided taste for music and takes much delight in playing with the piano. His speech is very imperfect; he speaks only a few words connectedly; he finds difficulty in making sentences longer than three or four words. His wants are made known chiefly by noung; verbs he uses with difficulty.

Physical Examination-Chilk, 37 inches tall; weight, $33 \%$ pounds. Complexion fair, hair straight and of ine texture, fontanels closed. Circumference of the head 19 inches, meatus to meatus 14 inches. Nose broad at base. Distanec between cyes 11/4 inches. Epicanthus present. Palpebral fissures oblique. Nystagmus present and narked. No fat pads in axillse or supraelavicular regions. Mouth hcld open, tongue protruding, but not swollen. Jungs normal at the present time. Heart normal. Little fingers both shorter than normal and curve insard.

Thyroid treatment has never been tried, the case being so elearly one of Mongolism that I felt it would be folly to use it. 810 West Central avenue:

Note.-The following authorfties may be consulted on the subject : Taylor: Nervous Diserses in Chlldhood and Early Ilfe.

Thompson: Clinical Examination and Treatment of Sick children.

Goodhart and Still : Disease of Children.

Jiolt: Diseases of Childhood.

Koplik : Disegses of Infancy and Childhood.

Barr : Mental Iefertives

Ireland : Mental Discases of Childhood.

Piaunder and Schlossman: The Liseases of Cblldren.

Allbutt: System of Medicine, rili, 236.

Watersol: Brit. Med. Jour, 1906, ii, 1701.

Neurath : Wien. med. Wchnsehr, 1907, Jvii, 1132.

Rearley: West. Cauada Med. Jour, 1907, $1,450$.

Haumann: Transvaal Med. Jour., 1906, 11, 107.

Sutheriada i Practitioner, London, 1904, Ixxifi, 821.

Satberland : Lancet, London, 1000, 1, 23.

West : Arch. Pediat., 1901, x viii, 918.

\section{A CASE OF SUCCESSFUL REMOVAL OF A CEREBELLAR TUMOR *}

THEODORE DILLER, M.D., AND OTTO C. GAUB, M.D. Neurologist and Surgeon respectively to the Alleghony General Hospital
PJT'Shotho

In a recent study Schuster, of Berlin, finds that ahout 15 per cent. of intraeranial tumors are situated in the cerebellum.

In his work on brain surgery, published in 1893 , Dr. M. Allen Starr collected 16 cases of cerebellar tumor in which opcrations had been done. In 11 of these cases the bumor was not found; of the other 5 patients, 3 died from the operation, and 2 cases the tumor was removed and the patient relicved. Writing again ten years later, including bis own personal experience up to that time, Dr. Starr collected 1,277 cases of brain tumor; of this number, he regarded 104 as operable. Among these 1,277 cases he found 58 cases of operations for cerebellar tumors. Dr. Starr gives table of operations for brain tumor ('l'able 1 ) :

TABLE 1. S'PARR'S TABTIE OF OPERATIONS FOR RRAIN

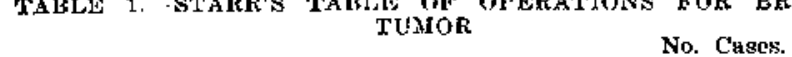

Cercbrum. Cerebejlum. Tumor found, removed, and patient recoverel. 154 Tumor round, removed and paflent died..... 5 rumor found, but could not be removed..... 22

lumor eould not be found...............

Total $5 \overline{8}$

- Rerd in the Section on Nervous and Mental Diseases of the Amertcan Medical Assoelation, at the sixtieth Annoal Session, beld at Atlantle City, June, 1009 .

1. Star, M. Alien: Organic Nerrous Dlseases, 1903.
Writing only two years later, in 1905 , Mills and Frazier were able to collect reports of 116 cases of cerebellar tumors in which operations had been performed; and they estimate that in 15 per cent. of these eases there wus "removal with reeovery."

Dr. Frazier, from a study of these 116 cases, has constructed the following table:

TAJLE 2.-I'JAZILR'S TAHLE'

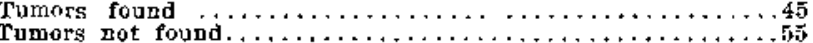

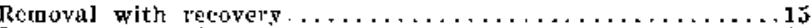

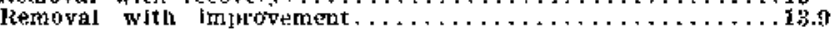

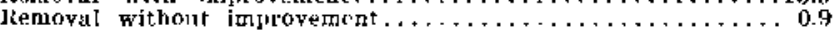

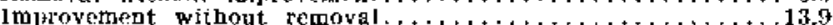

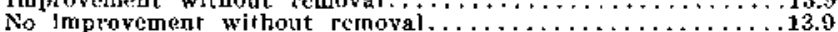
Neath when tumor was pemprod . and

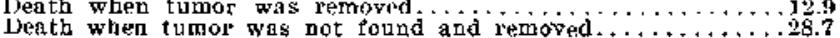

Comparison of statistics of successive dates, showing an increase in the percentage of recoveries and improvements and a reduction in the mortality, is given in Table 3.

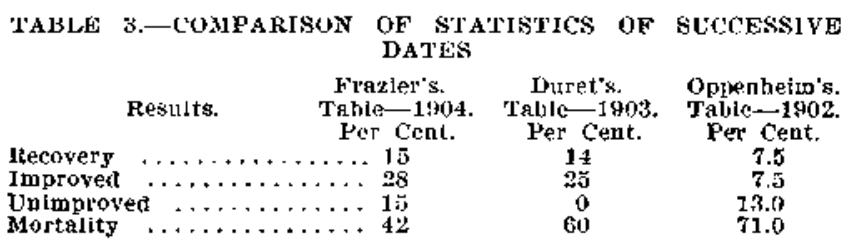

A comparison of the statistics of the total number of cases in Frazier's collection with the statisties of the last five years shows a manifest improvenent in the results as illustrated by $D_{r}$. Frazier in Table 4.

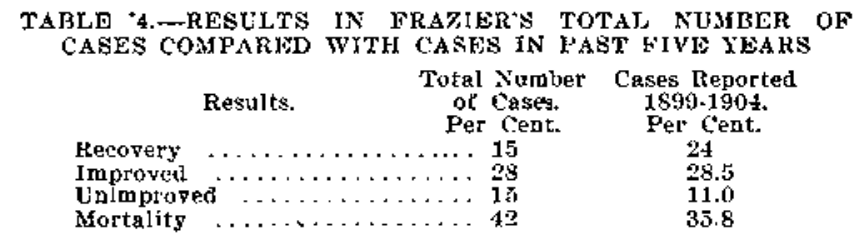

Dr. Frazier remarks:

From a review of these tables one is struck at once with the progress that has been made in this field of surgery from every point of view. T'he percentage of tumors is yeariy growing larger, the percentage of partial or complete recoverics is larger, and the mortality has fallen from 42 per cent. to 35.8 per cent. We believe that the results of surgical interventios on the cerebellar hemisphere will continue to improve, if not generally, at least in the hands of those who are giving this subject esnecial thought and attention.

We have gone over the table of 116 cases of ccrebellar tumor collected by Dr. Frazier; and in doing so we are not able to note quite as high a percenlage of cases in which the tumor was found and the patient recovered. From the study of this paper it appears to us that in per cent. of recoveries would be a fair allowance as against 15 which Dr. Frazier figures out. But thesc tables do indicate in a striking way that the mortality from the operations has been considerably reduced and the percentage of recoveries considerably increased in the last few ycars. In six cases in which Dr. Frazier operated the results were as follows:

One dicd after the first stage of operation; two recovered after removal of tumor; one relieved after evacuation of cyst, no recurrence more than a year after the operation; nne considerably improved after palliative operation; one no improvement; tumor not found.

Dr. Harvey Cushing, of Baltimore, as is well known, has Inade a number of special detailed studies of the operations for intracranial growths; being anxious to learn of his experiences in cerebellar operations up to 
date, we wrote to him, and he kindly responded with the following letter which sufficiently explains itself:

The following sunatary is complete so far as I can tell from a fuivly careful survey of the hospital files and my own pri. vate records, I have never had occasion to look these things up before as an especial group and there may be a few omissions.

I jave had thirty cases of known or presumed cereliellur tumor which have been subjected to the bilateral suboccipital operation which I favor through a "cross-bow" incision with permanent removal of the bone.

In this series there have been two deaths that can be directly attributed to the operation, both of them among the early cases, one patient with a vascular tumor of the vermiform process operatel on in a comatose state, who died from hemorrhage into the fourth ventricle; the other a patient with a benign cerebellar pontine endothelioma, who died fron preumonia on the seventh day. This was before the adoption of the cerebellar table with the shoulder-supports. These are the only cases in which there has been any operative colnplications of any kind. The wounds in all other eases hare healed per primam.

In eleven cases the tumor has been found and removed, or a simple (?) cyst evacuated.

Intrucerebellar.--More or less solid tumors, three; cysts eqacuated, four.

Extracerebellar,-Four.

Tumors found and considered irremovable, with no improvement after simple decompression, two.

Tumors not found, the operation resulting in a simple suboccipital decompression, twelve.

In two cases from the latter group I have operated some montbs la.ter at a second session and found and evacuated an intracerebellar cyst on each occasion. One of the patients was operated on elsewhere and a solid tumor, which was not apparent at the time of the first operation, was found and removed.

It is my feeling that with a proper face-down position on a suitable operating table, with a skilled anesthetist and with a Iow operation with removal of the posterior balf of the foramen magnum so as to get below the lips of the cerebellum and evacnate fluid before the dura is freely opened, these cases, contrary to the opinion that has been expressed by others, are favorable, if not more favorable, for operation as lesions of the cerebral hemisphere.

It is earnestly to be hoped that Dr. Cushing will, before long, publish his experience with cerebellar tumors in detail. For certainly the results he has at tained should inspire us all with a more hopeful view of cases of this character.

In view of the experience of the immediate past these records of Frazier and Cushing are certainly most striking and noteworthy ones. And they abundantly indicate that there is a fair meastire of chance for these poor patients suffering from cerebellar tumor when they are operated on by skilled surgeons who are specially trained for this work and who have their hearts in their work.

But not all investigators are able, like Frazier and Cushing, to see that the results of cerebellar operations are growing more favorable; and this other side of the case is well shown by Knapp of Boston.

Knapp ${ }^{2}$ has made several studies of brain tumor from the standpoint of the operation. In a paper published recently (1906) he concludes from the study of 104 antopsies of brain tumor that only four were anatomically accessible and presented enough clinical symptoms so that they might have been localized for the purpose of an operation.

Knapp presents the following tables of operations undertaken for the removal of brain tumors of all sorts:

2. Knapp: Boston Med. and Surg. Jour., Feb. 1, 1006.
TAB!S 5-KNAPR'S 'JABLL" OF" PERELN'SAGE OF FAILUIES TO FIND GITOWTH

\begin{tabular}{|c|c|}
\hline red ... & $\begin{array}{cc}1889 . \\
\ldots \quad 18 \\
\ldots \quad 5\end{array}$ \\
\hline
\end{tabular}

'ABLE 6.-KXA1'"S TARIE OF PLICENTAGE OF F'ALURE TO IRESVE:

1889. 1891. 1890. 190\%. Tatal

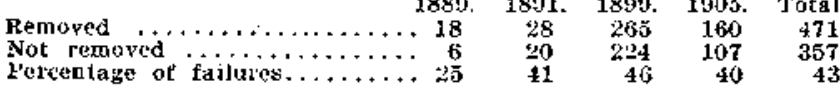

Besides the rases of operations for cerebellar tumors recorded by Mills and lirazier, several additioual cases have come under our notice as follows:

Stewart ${ }^{3}$ reports forty cases which he has analyzed. What ion Sinklert also reports three eases. In two instances an operation had been performed. In these two cases one patient, who had a cyst, recovered. He was in perfect health seven months after the operation. Dercum also discusses the subject.

Martens and Seiffert ${ }^{6}$ report the case of a boy of 13 on whom an operation was performed for removal of a cerebellar tumor. 'The patient died after a few hours. An autopsy revealed a tumor, a large glioma, in the fourth ventricle.

Savagc ${ }^{7}$ furnishes notes of eleven eases, ten of which were relieved by trephining.

Fuakenstein ${ }^{8}$ reports five personal cases as follows: (a) patient died from operation; (b) patient died without operation; a solitary tubercle on the right auditory nerve; (c) neurofibroma on the auditory and facial nerves; (d) sarcoma of the cerchellum; (e) encephaloma of the left posterior fossa.

Becker reports a case of tumor removed from the left pontocerebellar angle. The patient died in three hours after the operation. A beautiful plate shows the tumor in situ and another, the brain with the tumor removed.

W. B. Warrington ${ }^{10}$ reports a case of an operation for the removal of a cerebellar tumor. The tumor was not found and the patient died. An autopsy discovered a sarcoma the size of a pigeon's egg in the right lobe pressing on the middle of the medulla.

Poppert ${ }^{11}$ reports one case of successful removal ant one of a partially suceessful removal. From one patient a woman, aged 28 , a tumor was removed from the cerebellum, and four weeks later, at the time the report was made, she was doing well and greatly relieved, although the operation was done too late to improve the eyesight.

B. Sachs ${ }^{12}$ reports thrce cases of cerebellar tumor in which operations were performed. Two of the patients succumbed. In the third case the patient was greatly relieved, although the tumor could not be found at the operation. He remarks: "Cerebellar surgery is in a sad plight." He believes that "the cure of cerebellar tumors is difficult to attain execpt in a small proportion of eases," but he believes that much relief may be afforded by trephining operations.

Ascoli ${ }^{13}$ reports the case of a boy, aged 14, with cystic gliosareoma in the right lobe of the cerebellum

3. Stewart: Brala, 1904, p. 522.
4. SInkler. Wbarton: Three Creg of Cerebellar Tumor, THE Jouksal A. H. A., Sept. 26,1908 , ii, 1057.

5. Jercum: Jour, of Ment, and Nerv, Dis., 1906 , p. 169

f. Martess and Seittert: Berl. klin. Wchnschr. Aug. 10, 1908.

7. Savage: Berl. klja. Whonschy., Aug. 10, 1908.

8. Frnkenstein : Mitt. a. d, Greorgeht, xj11, 1732.

9. Becker: leutsch, Arch, f, kilb. Med. Jxrxix, p. 6

10. Warriagton, W. B. : Med. Chron., 1905, p. 144.

11. Poppert: Deutsch. Med. Wchnseb., 1907, No. 15, p. 613

12. Sachs, B. : Meti. Rec., Dec. 2\%, $190 \%$

13. Ascoll: Corrlere San., Mulan, xvill, 172. 
3 cnl. from the surface and a little anteriorly. Two operations were done two days apart. The tumor was not removed entirely. The patient died fifteen days later.

He reports another case ${ }^{14}$ of a woman, aged 23, who was operated on early in August, 1906, for cerebellar tumor. No tumor was found at the operation, but a few drops of pus of tuberculous character was discovered. By the middle of August the symptonts again beearme exaggerated. The patient died September 20 . An antopsy revealed a tuberculous node in the left cerebellum and a tuberculous area on the surface on both sides of the nedial lobe superior.

With this brief survey of the literature, we desire to give the clinical and pathologic records of a case observed by us, in which a tumor was removed from the cerebellum, the patient surviving the operation and exhibiting complete relief from headaches and vomiting and very great improvement of vision and considerablo improvement in his gait.

The patient was admitted to the Allegheny General Hospital Jan, 4, 1909, having been referred to Dr. Diller by Dr. J. J. Emmens, of Somerset, Pa., who had previously made the diagnosis of cerebellar tumor.

\section{CASE REPORT}

Patient.-A single man, aged 20. His father is sipported by charity. At the age of 2 the patieni was given out by the Children's Aid Association to a farmer. He was healthy and strong and after he grew up did good work about the farm. At the age of 18 he secured his release and wandered about a good deal; and it is thought he was rather wild. Six months ago he returned to the farn. For some time before his return he had been sutfering from headaches; and soon after he eame back to the farm he fell quite a distance from a bay wagon and struck his head. But it appears he had headaches before this accident. Three or four montha ago the headaches became very severe and very frequent. For three weeks past he has had very severe hesdaches located at the top of the head and pain runniug down the spine. His head now became drawn forward and to the left. He became intolerant of light; and his pupils were dilated. He had lately been subject to muny dixzy spells and very marked right-sided sweating. There has been no fever. Hearing in tlee right ear is some. what impaired. He is still able to read the newspaper.

Examination (Dr. Diller).-The posture at once conuands attention. 'The patient's head is bent forwar' on the chest and drawn toward the left and rotated on its axis toward the right. Efforts to straighten it up cause great pain. He assumes this position to relieve himself of pain. He walks in a slow, latorisus fashion with feet wide a jaxt; his gait is very weak and nncerlain. But he can walk the length of the ward with a little assistance. Four or five times he staggered so that lie had to be supporter, and at times he a]ways staggered toward right. At a subsequent test he staygered to the left two or three times. He is generally weak and wretehed, but I find no particular palstes of the trunk, urmis or legs; and I note no cranial nerve palsies. In a mental way he exhibits nothing significant except that he is overly quiet and subdued and bas a desire to be let alone. He is perhaps a littie dull.

Eyes: There appears to be marked nearoretinitis in the right cye. I could not get a satisfactory look at the left eye. ground.

Kars (Dr. Barndollar): Examination is negative. Hearing in both earg is normal.

Diagnosis.--The ease appears to be one of cerebelar tumor. The cvidence as to which side of the cerebellum is involved does not seem clear.

Course of Disease--Jan. 18, 1909. Dr. Heckel found 513 . of swelling in each nerve-double optic neuritis. The patient

14. Ascol1: Pollelindro, Rome, 1907, xf7, 141. has had several attacks of vomiting at the hospital. His lieadaches appear to be very severe and are located chiefly at the back of the head. Fis head is rotated to the right side, but pushed forward to the left.

January 26: Ben's headaches continue to be severe and lo complains that his eyesight is rapidly failing; that lie can hardly see to read at all, even large print.

This unfortunate man presents a most pitiable sight. Sitting up in bed, with his head driswn forward, his manwer and appearance indicate the truthfulness of his agsertion that the head pains are unceasing and very severe most of the time. He has vomited frequently and obtained very, very little sleep since he entered the hospital because of the pain. The poor fellow gladly welcomed an operation, although its serious character was made plain to him.

Operation (January 27).-Dr. Gaub operated today, exposing both lobes of the cerehellum. The right lohe was found more protruding than tlee left and sefter in consistency. About one-third or one-half of this lobe was cut away and the finger thrust forward to the anterior margin of the cerebellum; and a tumor was withdrawn sonewhat almond-shaped and about as large as a hickory-nut. The patient stood the operation well, but the night following the operation his pulse became very rapid, going up to 190 by midnight; and for several hours it was more rapid than this and eonld not he properly counted. By the next day it was down to 136 ; but the pulse has continued to be more or less rapid even up to the present time (March 16).

\section{DESCRIPTION OF OPERATION BY DR, OTTO C. GAUB}

The patient. was placed on his left side and a sandbag planed under his head. He was supported in this position by neans of a reinforced plater bandage passing around the upper part of the right arm and attached to an ordinary leg-holder. This posture gave a fair operative field and was comfortable to the patient, owing to his fixed head flexion. Ether anesthesia was used.

A cross-bow incision was made, the bone over both inferior occipital fossa was removed by means of chisel and rongeur forceps, impinging on the foramen magnum, lenving a strip covering the occipital sinus. The bone of the right side was of the thickness of ordinary parchment paper, while that of the left side was three times as thick. The dura was opened by a crucial ineision over both lobes of the cerebellum. Pronounced bulging of the right cerebellar lobe was noticed imnediately on exposure, and its color appeared deeper than iis fellow; its appearance was suggestive of softening. Palpation of both lobes demonstrated marked softening of the right lobe; and an attempt to introduce a spatula underneatl produced a tear of its substance. It was readily seen that a sutisfactory exploration was impossible without destroying the right lobe; so the index-finger was introduced and at a point, judged to be at the anterior surface of the right lobe, about its middle, a suiooth rounded mass the size of a hickory nut, of firmer consistency than the surrounding cerebellar tissue, was folt and then enucleated.

The removal of the tumor and softened exrebellar tissue was followed by a free hemorrhage controlled by packing with iodoform gauze. Up to this time the patient's condition was satisfactory; but following the removal of the tumor with its accompanying hemorrhage bis condition became grave. The blood pressure fell to $90 \mathrm{~mm}$. of mercury. $\Lambda$ rapid closure of the wound was made with eatgut for mnscle and fascial layers and isterrupted silkworm-gut sutures for the senlp. The incision over the right lobe was closed last, after the removal of the gauze tampon; no drainage.

Eight hours following the operation, the patient's condition was tunsatisfactory. He lay on his left sjde, his head supported by one pillow. The dressings were soaked with blood, the skin relaxed and perspiring, pulse 140. He was propped up, supported by a back rest and grain 1/120 atropin sulphate administered, following which tlie pulse rate became increas. ingly rapid so that it was impossible to count, although each pulse move was distinet.

I believe this extreme rapidity to have been due to the atropin. The further progress of the patient had been detailed. 
Immediately following the operation there was a fery slighlt rise of ternperature, $\mathbf{b} y$ the 2 ! $t_{1}$ the temperature was normal and remained so except that on February 8 there was an elevation to 101.6

\section{F'LBTHLE NOTE IJY DR, DII.I.ER}

On the 29th it was noted that the pulse was intermittent and it continued so for several days, being very markedly so at times.

On February 7 the patient's respirations suddenly becume rapid, going up to 40 per minate and his temperature to 101.6 ; and he seemed a little dult. I found a rough murmur over the heart which was apparently mitral-regurgitant. Dr. Emmens informed me that he examined the patient's heart carefully just before he came to the hospital and found no evidence of valyukar heart tronble. When the patient left the hospital this murmur was much less marked.

Excepting the above complications the patient's condition following the operation has heen extremely satisfactory. He experienced completo relief from headaches and vomiting; the optice neuritis subsided.

One of the most interesting and gratifying features of the case was the ripjid subsidence of the optic neuritis, which began the day following the operation and continued for sevcral days and there was a corresponding improvement in vision, which went hand in hand with it. Optie neuritis had been noted by Dr. Emmens before the patient entered the hospital; and the examination at the bospital on .January 5 revealet its presence in a high degree. The week preceding the operation the patient's vision was rapidly failing; so that the

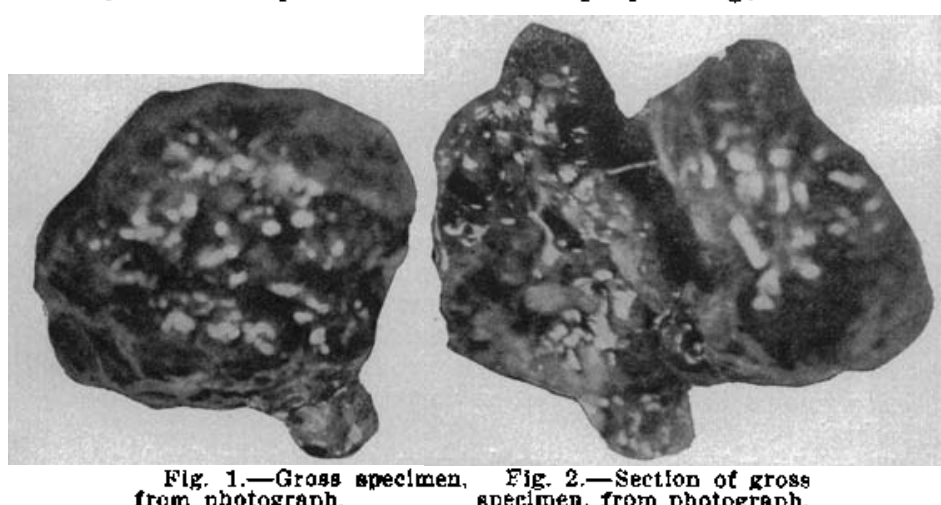

day before the operation he could hardly read the largest letter's in the advertisements of the newspapers. Dr. Heckel obsersed the patient at frequent intervals following the operation and has kindly furnished us with the gubjoined report, which speaks for itself.

EXAMINATION BX DK. X. B. HKCKEL.

"First examination, Jan, 18, J909: A typical papilledema (choked disc) with an elevation of the optic disc of five diopters, above the fundus, in each eye.

Jan. 26, 1909 (day before operation:)

o. D. about 6 diopters.

O. S. alont 5 diopters.

First day after operation:

O. I), about is diopters.

O. S. ahout 4 diopters.

Second day after operation:

O. D. about 3 diopters.

O. $S$. about 3 diopters.

Fourth day after operation:

O. D. about is dionter.

o. S. uhont 2 diopters.

Fifth day after operation:

O. I). about the sirme.

Sixth day after operation:

Outline of optic dise just leyinning to sinow in left eye.

Serentia day after operation:

Optic disc level with fundus.

Outline of optic dise in 0.5 , more pronounced.

Eightl day afier operation:

About the same.
Fourteenth day after operation.

Outline of optic disc anore distinet.

Sixteenth day:

Optic disc still blurred in 0 . 1 .

o. s. quite normal.

Mareh 16,1000, R. V. $=20 / 30:$ L, V. $=20 / 40$

Error of refraction, 0. D. +0.50 D. S. $=+0.50$ D. C. ax, $75^{\circ}$ O. S. $+0 . \overline{0} 0$ D. S. $=+0.50$ D. C. ax. $90^{\circ}$.

p. a. Jaeger N. 1 with $0, \mathrm{D}$.

p. a. Jaeger No. 2 with $0 . S$.

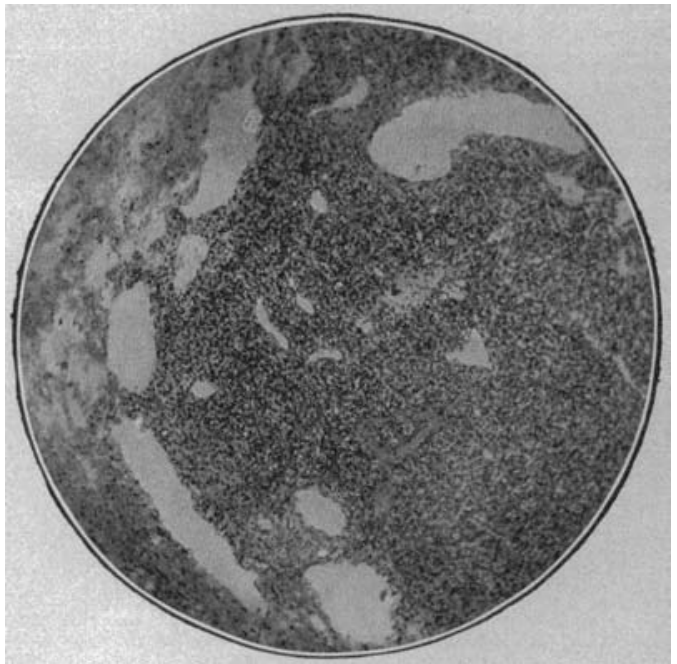

Fla 3-Jow-power view of section of specines: neular 4, objextivo $1 ;$ flom mierophotograph.

"The optic dise of the $O$. S. is a trifle paler than the optie dist of the $O$. D.

"One of the mont striking features of Ren's cyes was the greater elevation of the optic disc in the right eye; and the swellingr was slower in disappearing than in the left eye. This point of the greatox swelling in one nerve may be an aid in locating the tumor, i, e, right or left-sided."

\section{REMARKS RY IDR. DILLER}

Ben passed an examination for train service on the Baltimore und Ohio Railroad within the last year.

'lhe patient himseif noted sone improvement in his vision

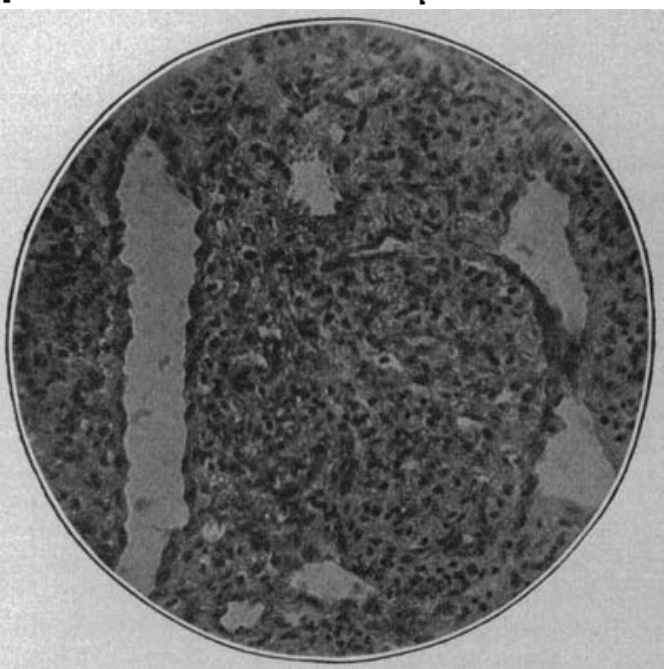

Fig. 4-Vjow of section of specimen. ocalas th, objectipt 5 : from miciophotopraph.

the second day after the operation and steady improvement from then alterward doring the rext three westis, at the end of which time lie conld readily read all the ordinaty print in 1 hit. newspapers.

The attitute of the head which had becn so striking was no itunger noted, 'jle patient romplained of no dizimess or nausea, or indeed of any distressing symptoms whitsoever. 
It was very cheering to hear the patient's response to inquiries. "How is your incadache?" "I have no headache." "How is your sight?" "Why, that's good now." At the tims that the patient left the hospital, on Mareh 22, he was comfortable and cheerful, but not yet able to walk more than a short distance; and he was still quite uncertain in his gait. But even his gait was rapidly improving. The heart murmur was still quite audible.

Ben left the hospital, March 22 , about eight weeks aiter the operation. After he had been home six weelss be wrote a very cheerful leter, reporting on his condition, from whicit we abstruct the following: "I got here all right. I have been visiting ever since. I am feeling pretty aood at present. I am walking around every day to get exercisc."

A more recent repori front Dr. Fimments also assures is that the patient continues to do well. ${ }^{15}$

The tumor was given to Dr. F. Proescher. 1;athrologist of the Allegheny General Hospital, for examination, and he reportell as follows:

PATHOLOGIC REPORT HY IJR. F. PLOESCIHER

The specimen is a very soft round tumor, $4 \mathrm{~cm}$. in diameter and $2 \mathrm{~cm}$. thick. It was partly surrounded by a red fibrous capsule. When eut in two its periplery was redishly-yellow,

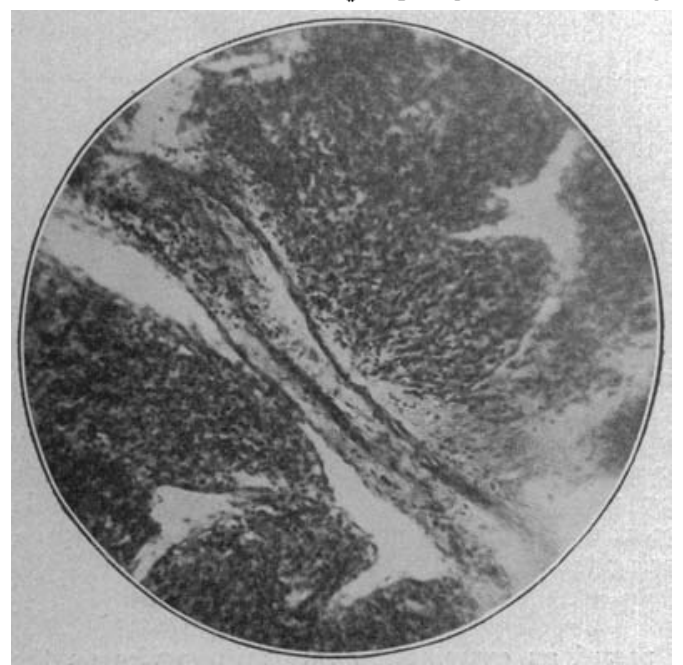

F Fig. 5-Tumor relis tnfitrating walls add lumen of vein.

npaque, very soft and rich in blond vessels. The center of the tumor had the consistency of gelatin, was grayisli-wbite and transparent and eontained many hemorrhagic areas.

Microscopic sections showed a polymorphous sareona with myxomatous areas. It contained many large and small blond vessels, some of which the sarcoma perforated and there were multiple hemor'rhages.

Diagnosis-Myxnaroma teleangiestatum.

The features of this case which apprared to us as noteworthy are:

1. The excellent recovery of the patient after the operation and his great improvement.

2. The position of the head, bent forward to the left on the chest and rotated to the right. This is against the common statement that in cerebellar tumors the head is drawn backward.

3. The very rapid subsidence of the optic neuritis following the operation.

4. The fact that the optic nenritis was greater on the right side-the side of the tumor--than the other side.

15. The patient was shown at the meeting of the Section on Nervous and Mental Dfreases of the American Medical Associatlon at the Atlantic City meeting. June, 1909. At this time he was able to read readily an ordinary newspaper and he walked pith ease an ordlinary pace. extibiting but slight trace of the marked ataxia which be had formerly had. The right buee-jerk was nor
mal: the left, somewht cxaggeraled. The pupils reacted to ljgbt ma] " the lest, somewhat cxaggera1ed. The pupils reacted to hgbt
the fundus was not examived. The pallent's bead was held in nearly normal position, although movements were somewhat, not greatly. restricted. In every way he was quite comrostable. The vound had entirely bealed.
5. The great practical value of exposing the cerebellum over botl sides; this, not only because it is frequently difficult to decide on which side a tumor is located, but because such an opening allows for far better manipulation and exploration of the cerebellum. Without this double opening the tumor in this case could probably not have been enucleated.

6. The fact that considerable manipulation and even destruction of the cerebellar lobe is compatible with life.

$\tau$. The position of the patient on the operating table and the surgical technic are of the greatest importance.

8. The earliac complication-the apparent derelopment of an endocartitis which seems to have disappeared now.

9. kight-sided sweating.

Westinglouse Building.

\section{ABSTRACT OH DISCESSION}

Dr. B. SACrs, New York: The matter of greatest iniport. ance is to determine the exact Jocation of the cerebellar neoplasm: and a considerable experience has led me to the conclusion that aecurate localization can only be made by the ohservation of a few especial and very delicate symptoms. The attitude of the head is one of the nost important of all signs. I lave found it of importance in a corsiderable number of cases; and my impression has been that for the most part the hear inclines toward the side on which the tumor is situated, although there may be cases reported in which the opposite has been true. Moreover, the occurrence of vertigo on looking to one side or the other sometimes leads to a clifferential diagnosis. And in that case, too, so far as my ex. perience goes, the vertigo becomes extreme if the person looks also toward the side on which we believe the tumor to be situated and where it is subsequently found. Another point of importance as an aid to tiagnosis in cerebellar cuses is the occurrence of intense nystagmus. While nystagmus is an associated yyntom in neoplasms in various locations, there is very intense nystagmus associated with this class of ncoplasms that I think muy be considered as evidence of cerebellar tunors in contradistinction to tumor in other parts of the brain.

Then the minute differences between the reflexes (and ali these symptoms are apt to be slight), partirularly slight ataxia in one nember as compared with the nuember on the opposite side of the body, are important.

Dr. Diller has been extremely fortunate in his diagnoses; for in a series of twenty cases of cerebellar neoplasm it has been my misfortune not to he able to localize the neoplasm in any apinal part of the cerebellum and yet the cerebellar operations will not be such an infrequent oecurrence. becanse nowadays we are impelled to exploratory operations in order to save vision. For that reason I do not hesitate in any case in which 1 suspect a cerebellar neoplasm to have the first $\mathrm{cx}$. ploratory operation done for the purpose of saving the vision if possible; and incidentally have that exploratory operation dune in such a way that it would be performed on the side to which the symptoms appezr to point. In that way we may sometines have all the good fortune that Jr. Diller lias hat in tlits case.

1). Max Marrfonse, New Haven: A year ago I was fortunate enough to see two cuses of cerebeliar tumor within timee montlis; and I had two particularly important aids to localization in these two cases: One was ataxia shown by the finger to nose test on the same side as the tumor, which ataxia is now considered to be a homolateral symptom. The other was awkwardness in the pronation and supination of the forcarm, present in both cases, that awkwardness bsing on the same side as the tumor. Those two phenomena aided me jis localization, und the tumor was found in eacli case where these ataxic conditions indicated.

One of the cases unforturately was very late in eoming to hand. It had been diagnosed by the general practitioner as neurasthenia and the patient liad been sent into the country and rusticated for three or four monthe before reaching my 
hands. In both of these cases the early and marked development of choked disc and tle persistent and early development of vomiting helped to point toward the cerebellum as the seat of the lesion.

DR. Georok B. Mojees, Denver: Nothing las been suid with reference to the utilization of the $x$-ray in these cases. I feel somewhat hesitant in bringing that up, although in threc cases in Denver prior to doing either an exploratory or ameliorating operation, 1 had the side in which I suspected the tumor to be present $x$.rayed, keeping that side closest to the plate.

In two instances I obtained very good shadows. Both of the patients were operated on and the diagrosis and location verified. One of these cases, like the one mentioned by the previous speaker, was diagnosed as a case of neurasthenia. but it hixd all the cvidences of a left-sided cerebellar tumor with secondary atrophy incident on the choked dise. In that case the patient was placed un a plate and photographed with the left side down. Tlke skiagram showed a very clear ont. line.

Those tumors which are, bowever. more deeply seated should not be expected to give a clear and definite outline, as compared with those which are located near the cortex. Naturally, the line of such tumors will be more or less dif. fuse. But with those loculed nerr the cortex if that side of the heal is brought next, to the plate, the skiagram will furnish a very important aid in determining the location of the tumor.

DR. B. R. Trcker, Ricltmond, Va.: l have a case whish \& think is undoubtedly one of cerebellar tumor, it which $I$ have advised operation, but I am very uncertain, auxt in fact, completely in doubt as to which side the tumor is on. The patient is a ehild about 4 years old who has nystagmus, nausea, vomiting, and optic nenritis which had gone on to atrophy. The position she takes is unique. She has spells of drowsiness, and then she wisk kneel on the floor, put her head on one side, resting it on the fioor, sometimes on the right and sometimes on the left, and drop off to sleep in. stantaneously. I have not been able to find another instance of a similar position assumed by the head and also by the body.

Dk. T. M. T. McKennan, Pittsburg: There are three sug. gestive points in diagnosis which have not been brought out, but which $I$ noticed in the case which is under discussion. One point is that while the patient had severe general head. ache, lhe stated that the most intense pain was on the right side and toward the back part of the head. The second point is that on palpation of the head, there was distinet tenderness on the right side; the third point is that there was unilateral sweating on the right side; all suggesting that th+ tumor probably was in the right cerebellum.

Dr. T. Drn.,.,. Pittshurg: I would be the last to minimize any aids that we would get in the way of localization, both as to whether a tumor is in the cerebrum or cerebellum and. if in eitier of these, in which portion. But the patient was not examined, I confess, with quite the same precisjon that le would lave been ordinarily: for, as I sail. he was so miserable and so rery wretclued that we could not examine him quite so thorougly in all respects as would have been de. sirable. I am glad Dr. MeKennan mentional these two or three points that I had forgotten in my brief sumnary of the case. A very interesting point was this unilateral sweating.

We should get all the aid we can and locate the tumor as exactly as possible; but after that from a practical point of view I think we ought always in cases of eerebellar tumor to opeI the sknll over both lobes of the cerebellum. This allows for a greater facility for exploration and also for a possible error as to the side the tumor is on; and since this is necessury for surgical purposes, it makes it less necessary to locafize a tumor exactly in the cerebellum.

I may say that since this ease I have had another tlat was not so fortunate. The tumor was enrrectly localized in the cerelellum on the right side, on the basis of the matred masseter involvement, as well as the sensory involvenient of the fifth nerve, and although the operation was done with the same care and skill as in the other case, the patient succumber very shortly.

\section{LICHEN PLANUS SCLEROSOS} WITH REPORT OF A CASE*

\section{JAY FRANK SCIIAMBERG, M.D. AND}

\section{ROSE HIRSCHLER, M.D.} PHILADELPHIA

Patient.-Miss L., American birth, aged 19; height about 5 feet; weight about 90 pounds; hair brown; eyes blue; skin fair with slight freckling; intelligent. Parents Irish, living and well. Several brothers and sisters living and well; one brother died in infancy of bowel trouble; no consumption in family; no skin distise; no history of syphilis.

History.-The patient had none of the infectious diseases that she could recall. About a year before examination she hatd lumbaro; since then had lad slight attacks of rhemma. tisn. She was not nervous in any way, i. e., her temperament was not neurotic. The patient siept well and ate well; she was actively engaged in work and was inconvenienced in no way by the skin disease present. She lad never had any ot ser skin affection. The disease under consideration made its ap. pearance about three years before the first examination. It is possible that it might lave begun sonewhat earlies, as the

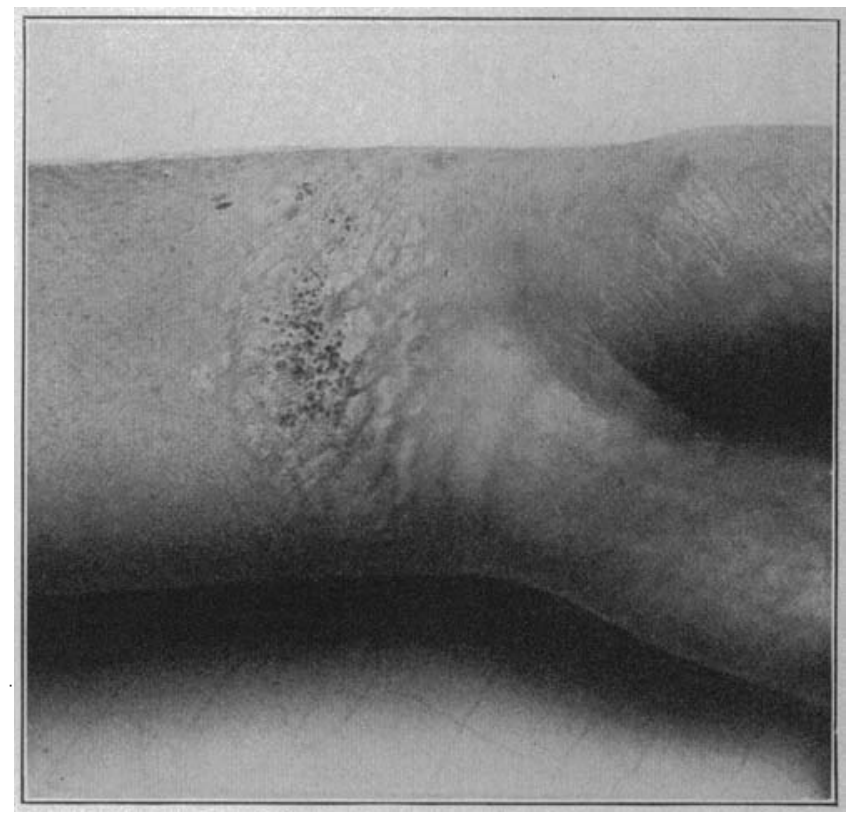

Fig. 1.-tiehen sclerosis, showing whitist papules and keratotie plugs.

lesions when first observel by the patient were alrendy large. The patient intsisted that the spots were w'ilte from the very beginning and that no redelish coloration was at that time present. Tlie palmar surface of the left wrist was first attacked and later the corresponding area of the right wrist. Seant, seattered lesions had sinec appeared on the dorsal sur. faces of the liands and fingers. A patch was also present on the posterior median aspect of the neck.

First General Examination.-The eruptive elements consisted of fat, shining, angular papules of a whitish hue. The discrete lesions were of a brilliant snow-white or bluish-white color; the confluent patches exhibited more of an opaque dead-white tint. The papules varied in size from a pinhead to a milletseed or larger. The snalier papules had a smooth surface and were but silightly, if at all, elevated above the level of the skin. On palpation, they were not more resistant than the surrounding integument. The larger patches were sliglitly raised above the skin. and somewhat resistant to the touch. The papules were irregularly facetted, their ancularity being profnced by the exaggerated furrows which constituted their boundaries.

* Fead in the Section on Dernatology of the Nmerican Medical Assutiation. at the Sixtieth Annual Session, lieid at Atlantic
Cily. lune. Jmm. 